\title{
Tooth Size Variation Related to Age in Amboseli Baboons
}

\author{
Jordi Galbany ${ }^{a, b} \quad$ Laia Dotras $^{c}$ Susan C. Alberts ${ }^{a, d}$ \\ Alejandro Pérez-Pérez ${ }^{b}$ \\ a Department of Biology, Duke University, Durham, N.C., USA; 'becció d'Antropologia, \\ Departament de Biologia Animal, Universitat de Barcelona, and ' Instituto Jane Goodall \\ España, Barcelona, Spain; ${ }^{d}$ Institute of Primate Research, National Museums of Kenya, \\ Nairobi, Kenya
}

\section{Key Words}

Molar size $\cdot$ Interproximal wearing $\cdot$ Aging $\cdot$ Papio cynocephalus $\cdot$ Amboseli $\cdot$ Kenya

\begin{abstract}
We measured the molar size from a single population of wild baboons from Amboseli (Kenya), both females $(n=57)$ and males $(n=50)$. All the females were of known age; the males represented a mix of known-age individuals $(n=31)$ and individuals with ages estimated to within 2 years $(n=19)$. The results showed a significant reduction in the mesiodistal length of teeth in both sexes as a function of age. Overall patterns of age-related change in tooth size did not change whether we included or excluded the individuals of estimated age, but patterns of statistical significance changed as a result of changed sample sizes. Our results demonstrate that tooth length is directly related to age due to interproximal wearing caused by M2 and M3 compression loads. Dental studies in primates, including both fossil and extant species, are mostly based on specimens obtained from osteological collections of varying origins, for which the age at death of each individual in the sample is not known. Researchers should take into account the phenomenon of interproximal attrition leading to reduced tooth size when measuring tooth length for ondontometric purposes. Copyright $\odot 2011 \mathrm{~S}$. Karger AG, Basel
\end{abstract}

\section{Introduction}

The study of postcanine tooth size is very common in primatological and anthropological studies. It provides information about tooth development [Reed, 1973; Godfrey et al., 2001], phylogeny and taxonomy [Hayes et al., 1990; Wood et al., 1991], adaptation [De Gusta et al., 2003] and feeding ecology [Kay, 1975; Teaford and Ungar,

\begin{tabular}{ll}
\hline KARGER & ( ) 2011 S. Karger AG, Basel \\
$\begin{array}{ll}\text { Fax +4161306 } 1234 & \\
\text { E-Mail karger@karger.ch } & \text { Accessible online at: } \\
\text { www.karger.com } & \text { www.karger.com/fpr }\end{array}$
\end{tabular}

Dr. Jordi Galbany
Secció d'Antropologia, Departament de Biologia Animal Universitat de Barcelona, Av. Diagonal 645 ES-08028 Barcelona (Spain)

Tel.+3493402 1460, E-Mail jgalbany@ub.edu 
2000] of fossil and extant primate species. Dental size has also been shown to vary between sexes in some primate species [Almquist, 1974; Wood et al., 1991], with sexual differences being particularly remarkable in the canines [Oxnard et al., 1985], but also in the molars [Garn et al., 1966; Cochard, 1987; Teschler-Nicola and Prossinger, 1998]. Dental size is traditionally evaluated by measuring the mesiodistal length and buccolingual width of the teeth [Sauther et al., 2001; Hlusko et al., 2002; Swindler, 2002], but some researchers have pointed out that this method for estimating tooth size can be problematic because of interproximal tooth wear [Swindler and Orlosky, 1974; Wood, 1981; Bermúdez de Castro et al., 1997; Teaford, 2000; Hillson et al., 2004]. To our knowledge, no studies have yet evaluated the effect of interproximal wear on tooth length in known-age populations of non-human primates.

Interproximal tooth wear is produced as a result of the different movements of teeth during mastication [Hinton, 1982], which generate interproximal attrition that wears away the rounded profile of the crown, and produces flattened wear facets that can represent a significant proportion of the unworn diameter [Wolpoff, 1971; Kieser et al., 1985; Cole and Smith, 1987; Wood and Engleman, 1988; Kieser, 1990; Delson, 1993; Kaifu et al., 2003; Hillson et al., 2004].

In dental morphology studies, when mesial and/or distal borders of the teeth are affected by light interproximal wear, the original edges are estimated by reference to the overall crown shape, as well as the buccolingual extent of the wear facets [Wood and Uytterschaut, 1987; Wood and Engleman, 1988; Bailey, 2004; Bailey and Lynch, 2005; Martinón-Torres et al., 2006; Gómez-Robles et al., 2007, 2008]. Because of this dynamic and cumulative interproximal wearing, it might be particularly interesting to analyze sex- and age-related changes in dental dimensions and how these changes affect the different teeth [Groves and Harding, 2003].

Dental studies in primates, including both fossil and extant species, are mostly based on specimens obtained from osteological collections of varying origins, for which the age at death of each individual in the sample is not known. In the present study we examined premolar and molar size from a single population of wild baboons of known ages from Amboseli, Kenya. The sample contained no geographic heterogeneity, and because we knew the actual age of the individuals in the sample, we were able to conduct a detailed study of age-related changes in tooth size in a wild primate population. The aim of this study was to determine whether the aging of teeth affects the size of premolars and molars to an extent detectable by researchers when measuring teeth using straightforward procedures.

\section{Methods}

Study Population

This study is based on a sample of tooth casts from yellow baboons (Papio cynocephalus) in the Amboseli basin, a semiarid savanna habitat $\left(2^{\circ} 40^{\prime}\right.$ south and $1,100 \mathrm{~m}$ above sea level) in southern Kenya, at the base of Mount Kilimanjaro. This area is near the northern limit of distribution of the species, and the animals in the study population exhibit some admixture with olive baboons (Papio anubis), which occasionally immigrate into the basin [Alberts and Altmann, 2001; Tung et al., 2008]. The Amboseli baboons have been intensively studied for almost 4 decades (see www.princeton.edu/ baboon for a complete bibliography and Baboon Project Monitoring Guide).

The study population consists of 5 social groups that have partially overlapping home ranges, and each group is the focus of detailed observations several days a week. All individuals 


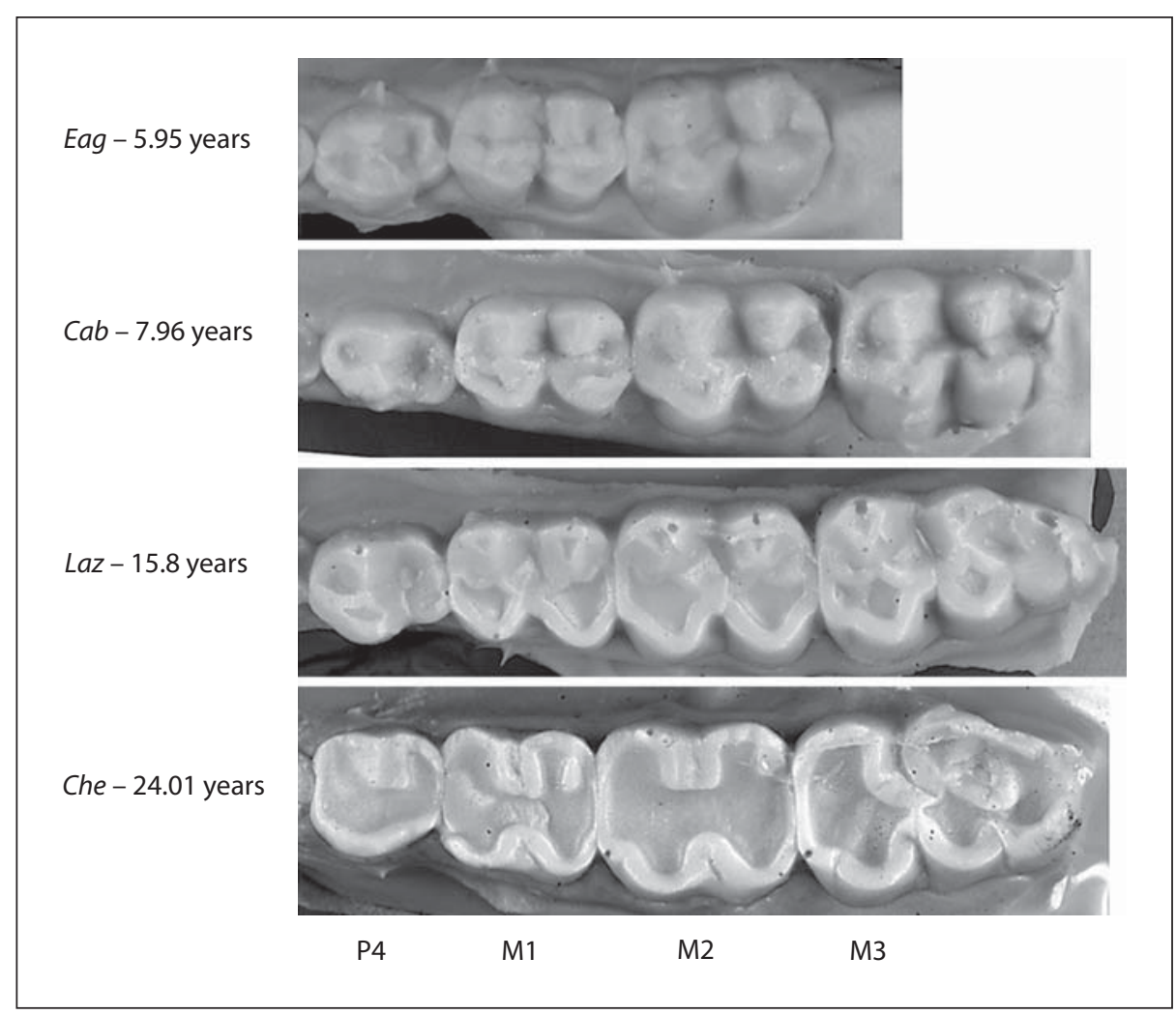

Fig. 1. Postcanine occlusal surfaces of 4 different Amboseli baboon females, representing different ages. Older individuals present higher occlusal and interproximal tooth wear.

in the study population are recognized on sight based on unique physical characteristics. Females in this species remain in their natal social group throughout their lives, while males disperse from their natal group at a median of 8.5 years of age (young adulthood [Alberts and Altmann, 1995]). All individuals born in the study population - females and males remaining within the study population even after dispersal from their natal group - were identified at birth and followed throughout their lives, or until they emigrated from the study population (in the case of males). Consequently, ages for all animals born in the study population are known to within a few days, including all the female subjects of this study and 31 of the 50 male subjects. Nineteen of the 50 males in this study were immigrants with estimated ages; males most frequently immigrated as young adults of approximately 8 years, but may have immigrated at any time during adulthood. Ages for immigrant males were estimated to within 1 or 2 years based on patterns of growth, maturation and change in physical parameters [Alberts et al., 2006; details in Altmann and Alberts, 2004]. The ages of female subjects varied between 4.51 and 26.35 years of age, with a mean value of 10.84 years, and those of the male subjects varied between 6.22 and 20.45 years, with a mean age of 10.96 years.

\section{Tooth Casts}

Between the years 2006 and 2009, a subset of baboons in the Amboseli population was briefly immobilized by a dart propelled from a blowpipe that delivered a dose of an anesthetic, 
Table 1. Basic statistics of tooth crown mesiodistal length in upper (superscript) and lower (subscript) premolars and molars in both sexes

\begin{tabular}{lrrrrr}
\hline Tooth & $\mathrm{n}$ & Min. & Max. & Mean & SD \\
\hline Females & & & & & \\
$\mathrm{P}^{4}$ & 56 & 5.26 & 7.04 & 6.15 & 0.42 \\
$\mathrm{P}_{4}$ & 56 & 6.61 & 8.46 & 7.42 & 0.43 \\
$\mathrm{M}^{1}$ & 57 & 8.79 & 10.84 & 9.74 & 0.51 \\
$\mathrm{M}_{1}$ & 56 & 8.32 & 10.42 & 9.34 & 0.48 \\
$\mathrm{M}^{2}$ & 56 & 10.04 & 13.06 & 11.39 & 0.62 \\
$\mathrm{M}_{2}$ & 56 & 9.91 & 11.73 & 10.85 & 0.50 \\
$\mathrm{M}^{3}$ & 32 & 10.02 & 12.42 & 11.41 & 0.60 \\
$\mathrm{M}_{3}$ & 31 & 12.51 & 15.21 & 14.06 & 0.75 \\
\hline Males & & & & & \\
$\mathrm{P}^{4}$ & 48 & 6.18 & 7.45 & 6.75 & 0.36 \\
$\mathrm{P}_{4}$ & 45 & 7.12 & 9.14 & 8.09 & 0.42 \\
$\mathrm{M}^{1}$ & 46 & 9.33 & 11.06 & 10.32 & 0.38 \\
$\mathrm{M}_{1}$ & 45 & 9.00 & 10.73 & 9.93 & 0.39 \\
$\mathrm{M}^{2}$ & 46 & 11.25 & 13.52 & 12.20 & 0.50 \\
$\mathrm{M}_{2}$ & 47 & 11.06 & 12.72 & 11.83 & 0.37 \\
$\mathrm{M}^{3}$ & 43 & 11.97 & 14.05 & 12.92 & 0.54 \\
$\mathrm{M}_{3}$ & 43 & 14.32 & 17.43 & 15.83 & 0.37 \\
\hline
\end{tabular}

$\mathrm{n}=$ Sample size; Min. $=$ minimum value; Max. $=$ maximum value; $\mathrm{P} 4=$ second premolar; $\mathrm{M} 1$ = first molar; $\mathrm{M} 2$ = second molar; $\mathrm{M} 3$ = third molar.

Telazol $^{\circledR}$. Various data were collected from each anesthetized animal, including tooth casts for morphological and dental microwear analysis. With the animals immobilized, enamel tooth surfaces were washed with pressurized water, using a manual water pump, and brushed lightly, by using a soft toothbrush, to remove food remains, and then dried with a foot-powered air pump for some minutes. Tooth casts were obtained for the left mandibular and maxillary rows, using Colténe ${ }^{\circledR}$ Speedex putty. The putty and the catalyzer were mixed rapidly and applied by hand, and pressed against all the teeth to insure good-quality replicas. When the replication material had totally cured, within 2-3 min, the mold was removed, labeled and stored in a plastic bag. From these negative molds, replicas were made at the University of Barcelona, using Feropur polyurethane $\left(\right.$ Feroca $\left.^{\circledR}\right)$, which is stable, has excellent fluidity and is an easy-to-use casting material with good hardness properties [Galbany et al., 2004, 2006]. Dental replicas (fig. 1) from 57 females and 50 males were obtained and analyzed in the present study.

Every individual was analyzed only once, providing a cross-sectional data set. From the casts produced, premolar and molar teeth (P4, M1, M2 and M3) were measured using a Helios digital caliper $(0.01 \mathrm{~mm}$ precision). The maximum mesiodistal diameter (table 1) was measured on the occlusal surface from the mesial to the distal interproximal contact points, in the middle of the interproximal facet, between tooth crowns [Swindler, 2002]. Coefficients of correlation (Pearson) were calculated to assess the relationship of premolar and molar length (' $y$ '-dependent variable) in relation to age (' $x$ '-independent variable). Most analyses were carried out using SPSS software version 15.0. The exception was our analysis of sex differences in the change in tooth size with age (see Results); for this analysis, we tested for male-female differences in the slope of the relationship between tooth size and age, using SMATR (Standardised Major Axis Tests and Routines) software [Warton et al., 2006]. 
Table 2. Linear regressions for predicting mesiodistal length from age in upper (superscript) and lower (subscript) premolars and molars in both sexes

\begin{tabular}{lllllll}
\hline Tooth & $\mathrm{n}$ & $\mathrm{R}^{2}$ & $\mathrm{~F}$ & $\mathrm{p}$ value & Equation & Power \\
\hline Females & & & & & & \\
$\mathrm{P}^{4}$ & 56 & 0.192 & 12.842 & 0.001 & length $=-0.036 \cdot$ age +6.548 & 0.96 \\
$\mathrm{P}_{4}$ & 56 & 0.210 & 14.351 & $<0.001$ & length $=-0.038 \cdot$ age +7.847 & 0.97 \\
$\mathrm{M}^{1}$ & 57 & 0.173 & 11.531 & 0.001 & length $=-0.041 \cdot$ age +10.196 & 0.94 \\
$\mathrm{M}_{1}$ & 56 & 0.268 & 19.814 & $<0.001$ & length $=-0.048 \cdot$ age +9.866 & 0.99 \\
$\mathrm{M}^{2}$ & 56 & 0.063 & 3.638 & 0.062 & length $=-0.031 \cdot$ age +11.726 & 0.59 \\
$\mathrm{M}_{2}$ & 56 & 0.055 & 3.172 & 0.081 & length $=-0.023 \cdot$ age +11.102 & 0.54 \\
$\mathrm{M}^{3}$ & 32 & 0.013 & 0.391 & 0.536 & length $=-0.013 \cdot$ age +11.594 & 0.15 \\
$\mathrm{M}_{3}$ & 31 & 0.018 & 0.528 & 0.473 & length $=-0.019 \cdot$ age +14.335 & 0.18 \\
\hline$M^{2}$ les & & & & & & \\
$\mathrm{P}^{4}$ & 48 & 0.003 & 0.123 & 0.728 & length $=-0.006 \cdot$ age +6.807 & 0.10 \\
$\mathrm{P}_{4}$ & 45 & 0.017 & 0.729 & 0.398 & length $=-0.016 \cdot$ age +8.263 & 0.21 \\
$\mathrm{M}^{1}$ & 46 & 0.024 & 1.098 & 0.301 & length $=-0.018 \cdot$ age +10.516 & 0.27 \\
$\mathrm{M}_{1}$ & 45 & 0.111 & 5.350 & 0.026 & length $=-0.038 \cdot$ age +10.342 & 0.73 \\
$\mathrm{M}^{2}$ & 46 & 0.011 & 0.473 & 0.495 & length $=-0.014 \cdot$ age +12.366 & 0.17 \\
$\mathrm{M}_{2}$ & 47 & 0.019 & 0.849 & 0.362 & length $=-0.014 \cdot$ age +11.987 & 0.23 \\
$\mathrm{M}^{3}$ & 43 & 0.002 & 0.085 & 0.771 & length $=0.007 \cdot$ age +12.841 & 0.08 \\
$\mathrm{M}_{3}$ & 43 & 0.022 & 0.903 & 0.347 & length $=0.032 \cdot$ age +15.460 & 0.24 \\
\hline
\end{tabular}

$\mathrm{P} 4=$ Second premolar; $\mathrm{M} 1$ = first molar; $\mathrm{M} 2$ = second molar; $\mathrm{M} 3$ = third molar.

\section{Results}

In these cross-sectional analyses including all females (all of known age) and all males (31 of known age and 19 of estimated age), females exhibited a significant reduction with age in the mesiodistal length of both the upper and lower P4 and M1 teeth (table 2; fig. 2) and also a trend in the reduction of mesiodistal length in the upper and lower M2. Males exhibited a significant reduction in mesiodistal length in lower M1, but in no other teeth (table 2; fig. 2). When we excluded males of estimated age and reduced our sample size to $n=31$ males of known age, we found a significant reduction in mesiodistal length in the lower M2, but in no other teeth (online suppl. tables 1 and 2, www.karger.com/doi/10.1159/000323588). Taken together, these results suggest that females showed greater rates of attrition than males. In addition, more teeth in females showed a significant amount of interproximal wear.

Rates of interproximal tooth wear could be calculated, by using the equations provided in table 2 and the age range of the individuals analyzed, at least for those significant relationships between tooth wear and age. In females, upper M1 exhibited a mean tooth wear rate of $421.2 \mu \mathrm{m} /$ year, and lower M1 exhibited a wear rate of $494.5 \mu \mathrm{m} /$ year.

To examine further the apparent sex differences in the relationship between tooth size and age, we calculated statistical differences between the male and female 


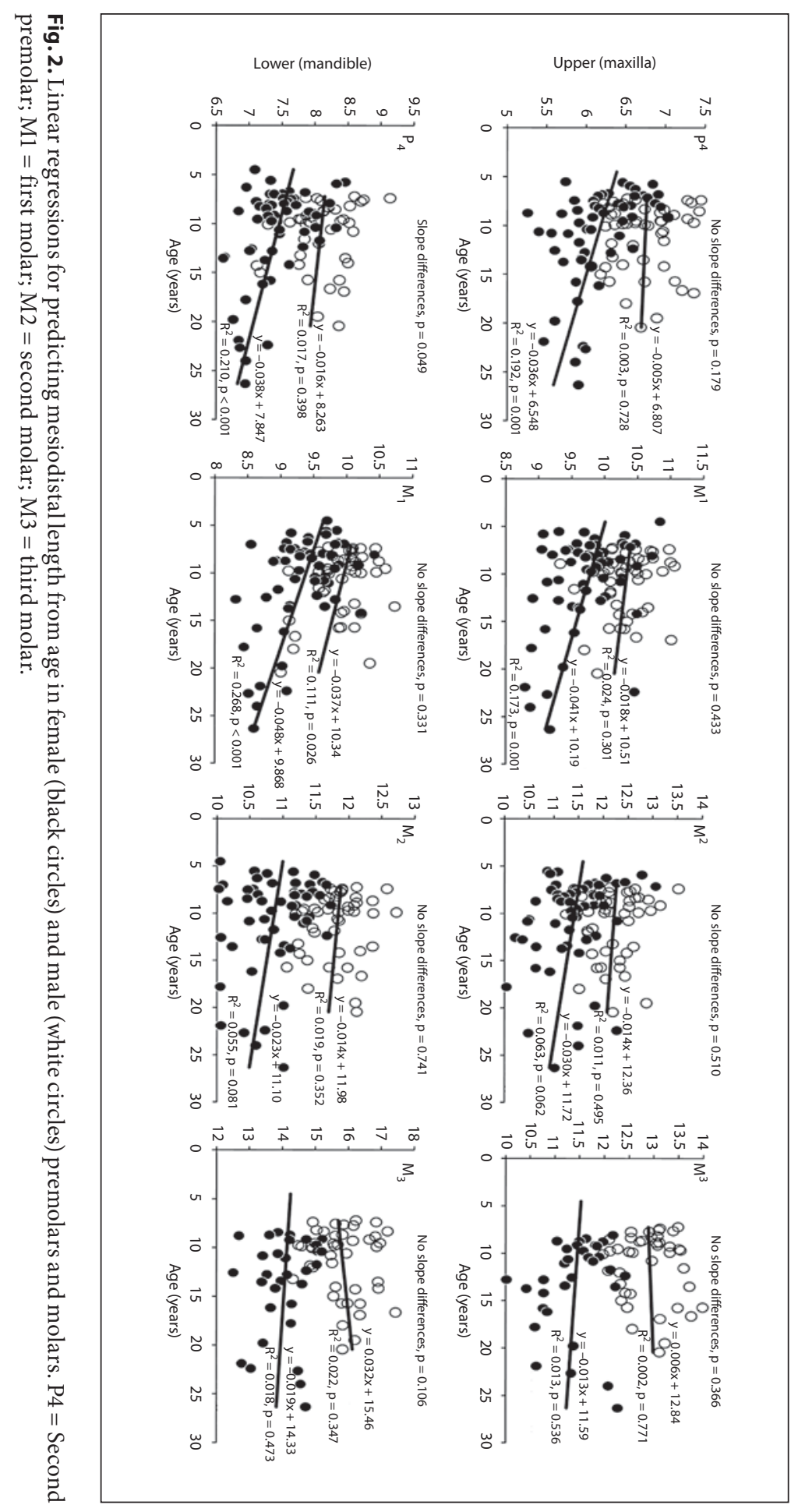


slopes of tooth size as a function of age (Methods). We found no significant differences between male and female slopes for any teeth, except for the lower P4, which showed a marginal difference ( $\mathrm{p}=0.049$, fig. 2 ). However, when only males of known age were analyzed, more slope differences between female and male regressions occurred, for the lower P4 ( $\mathrm{p}=0.003)$, lower M3 $(\mathrm{p}=0.015)$, upper P4 $(\mathrm{p}=0.010)$ and upper M1 ( $\mathrm{p}=0.023)$ (online suppl. fig. 1).

\section{Discussion}

\section{Tooth Length and Age}

Interproximal wear is a phenomenon thought to occur as a result of forces generated during the mastication process, which wear away the rounded profile of the molar crowns and flatten the interproximal facets, producing a reduction of the mesiodistal diameter. Although interproximal wear has been described in humans, hominids and fossil primates [Hinton, 1982; Kieser et al., 1985; Whittaker et al., 1987; Wood and Engleman, 1988; Kieser, 1990; Kaidonis et al., 1992; Bailey, 2004; Bailey and Lynch, 2005; Martinón-Torres et al., 2006; Gençturk et al., 2008], to our knowledge this study represents the first systematic measurements of interproximal tooth wear in a known-age population of any species of wild primates. Previously, Wolpoff [1971] had provided a very extensive study of interstitial or interproximal wear in humans, hominids and non-human primates, focusing on the causes of this kind of tooth wear and its relation to age, but using osteological samples for which the age of every individual was estimated from tooth eruption timing, even in the fossil samples.

Interproximal wearing is not the only transformation that teeth exhibit with aging. Numerous studies of dental ecology, based on primate field work, have demonstrated that teeth change with age, and that behavioral differences between individuals or populations can also affect tooth wear [Cuozzo and Sauther, 2010]. A number of studies have also examined the effect of aging on tooth functionality and the consequent effects of aging teeth on the fitness of individuals or populations [Cuozzo and Sauther, 2010]. Many studies show that occlusal tooth wear reflects age in wild primates (sifakas [King et al., 2005; Wright et al., 2008]; howler monkeys [Dennis et al., 2004]; baboons [Phillips-Conroy et al., 2001; Galbany et al., 2011]; lemurs [Zohdy et al., 2009; Cuozzo and Sauther, 2010]) and semi-captive primates (rhesus macaques [Kay and Cant, 1988]). Moreover, occlusal tooth wear in Amboseli baboons was also predicted by individual differences in feeding behavior [Galbany et al., 2011]. Among sifakas, King et al. [2005] related tooth wear to individual fitness, in that older females, with more worn teeth, lost their infants at higher rates than younger females [King et al., 2005]. In addition, many studies have examined dental microwear in primates in relation to ecology [Ungar, 1990; Teaford, 1994; Godfrey et al., 2004; Nystrom et al., 2004; Ungar et al., 2004; El Zaatari et al., 2005; Galbany et al., 2005, 2009].

Regarding interproximal wear, our results show a systematic, significant effect of age in premolar and molar length. Specifically, both males and females exhibited a significant reduction in the mesiodistal length of lower M1, and females also exhibited a significant reduction in the length of upper M1 and upper and lower P4. These results indicate that interproximal wear was more evident in those teeth that 
had the earliest eruption, particularly M1, which erupts first in baboons. In contrast, M3, which is the last tooth to erupt [Phillips-Conroy and Jolly, 1988; Kahumbu and Eley, 1991], did not exhibit significant length reduction in our sample (table 1), although this does not rule out the possibility that M3 experiences size reduction in very aged individuals.

Fayad et al. [2004] provided evidence, in humans, that eruption of M3 produces a mesial inclination in M1 and M2. This inclination increased with age, an observation that supports the idea of mesial drift produced by the anterior component of the occlusal force during the eruption of the later molars; this in turn would explain the relatively high degree of interproximal attrition in P4 and M1. Similar results have also been reported in humans, non-human primates and hominids, and experimental evidence indicated that only a very low mesial force was necessary to produce enough interproximal wear to cause a mesial drift [Wolpoff, 1971]. This mesial force might depend on several factors, including the eruption of molars, the mesial vector of tongue and buccal contraction or the action of occlusion on dental crowns [Murphy, 1964; Welsch, 1967; Southard et al., 1989, 1992]. Another factor that may be involved in baboons in the length reduction of P4 and M1 could be the forces of the canines on the postcanine dentition. The large maxillary canine occludes into the buccal diastema between the mandibular canine and the first premolar (P3), and the mandibular canine fits into the diastema between the maxillary canine and the lateral incisor. These robust teeth could apply a distal horizontal force on the postcanine dentition that also contributes to attrition in P4 and M1.

\section{Sex Differences in Interproximal Wear}

Although we observed differences between males and females in the rate of interproximal tooth wear, these differences were generally not significant, as indicated by the lack of difference between males and females in the slope of relationship between size and age in most teeth. When we restricted our analysis to males of known age (and incidentally decreased our sample size), the differences between male and female slopes increased.

These apparent sex differences, although not significant in most cases, could have 3 potential sources. (1) The sex differences could be attributable to statistical power differences [Uitenbroek, 1997]. Specifically, our male and female samples differed in size (we had fewer males than females in our sample; table 1) and in age distribution, which covered a smaller portion of the life span for males than for females (from 6.22 to 20.45 years in males, and from 4.51 to 26.35 years in females). (2) The sex differences could be attributable to greater error in our age estimates for males than for females. Error in the age estimates would have the effect of reducing the significance of any age effect in males, and this possibility is supported by the fact that the differences between male and female slopes increased when we restricted our analyses to males of known age. (3) Finally, the sex differences could be attributable to greater variance in the ages at which teeth erupt for males. If age at eruption is more variable in males, then that greater variability will reduce the age effect, even if males had as much interproximal wear as females. In fact, male baboons do show more variation in the age at tooth eruption than do females [Phillips-Conroy and Jolly, 1988; Kahumbu and Eley, 1991].

Sex differences in interproximal wear have not been found in human molars [Whittaker et al., 1987], but then humans are much less dimorphic than baboons. 
One might expect that the larger size and musculature of male baboons would contribute to greater tooth wear in males because they result in higher energy needs for males than females. In our baboon population, previous studies have not detected significant effects of sex on the proportion of time spent foraging for the wild-feeding baboons in the Amboseli population [Post et al., 1980], but males have priority of access to feeding sites, which allows them to have priority access to higher-quality food [Post, 1981]. Moreover, a recent study of occlusal tooth wear done on the same sample used in this study found no significant differences between males and females in occlusal tooth wear rates for any molar, but females always exhibited higher tooth wear rates than males [Altmann et al., 2010; Galbany et al., 2011]. This could be explained by slight feeding differences between sexes and fits with the interproximal tooth wear pattern found in the present study.

\section{Conclusions}

Measures of molar length in fossil and extant primates are used to draw inferences about feeding ecology, and they are also used in phylogenetic studies, and in studies of tooth development and sexual dimorphism. Our results are noteworthy because of the clear impact of age on premolar and molar length, and should be taken into account by researchers when measuring tooth length for any of these purposes. However, these results also call for studies of interproximal wear and tooth attrition in other primate species, in order to understand better the impact of age, sex and other variables in a wide range of foraging and ecological contexts.

\section{Acknowledgments}

This research was funded by the US National Science Foundation (BCS-0323553 and BCS0323596), the Princeton University Center for Health and Wellbeing (P30 AG024361), the National Institutes of Health (AG034513-01 and AG031719) and the Spanish CGL2004-00775/ BTE and CGL2007-60802 projects, and was supported by the 'Departament d'Educació i Universitats de la Generalitat de Catalunya - Beatriu de Pinós 2006BPA10118' and the 'Beca Floquet de Neu 2007-2008, Barcelona de Serveis Municipals SA (Divisió Parc Zoològic de Barcelona)'.

We thank the Office of the President of the Republic of Kenya and the Kenya Wildlife Service for permission to work in Amboseli over the years. We thank the Institute of Primate Research for local sponsorship in Kenya, the wardens and staff of Amboseli National Park, and the pastoralist communities of Amboseli and Longido for continuous cooperation and assistance. Particular thanks go to Raphael Mututua, Serah Sayialel and Kinyua Warutere for their contributions to all of the data presented in this paper, to Jenny Tung and Mercy Akinyi for particular assistance with the darting, and to Lacey Maryott and Katherine Fenn for their assistance with BABASE, the Amboseli baboon database. All protocols complied with relevant regulations in Kenya (Kenya Research Permits MOEST 13/001/C351 vol. II and MOS\&T 13/001/33c/79) and the USA (IACUC A0840903 at Duke University).

We are also grateful to Eric Delson (City University of New York), Christine Wall (Duke University), Jeanne Altmann (Princeton University), Alejandro Romero (Universidad de Alicante) and Núria Garriga (Universitat de Barcelona) who provided encouragement, very helpful comments and assistance. 


\section{References}

Alberts SC, Altmann J (1995). Balancing costs and opportunities: dispersal in male baboons. American Naturalist 145: 279-306.

Alberts SC, Altmann J (2001). Immigration and hybridization patterns of yellow and anubis baboons in Amboseli, Kenya. American Journal of Primatology 53: 139-154.

Alberts SC, Buchan JC, Altmann J (2006). Sexual selection in wild baboons: from mating opportunities to paternity success. Animal Behaviour 72: 1177-1196.

-Almquist AJ (1974). Sexual differences in the anterior dentition in African primates. American Journal of Physical Anthropology 40: 359-368.

Altmann J, Alberts SC (2004). Monitoring guide for the Amboseli Baboon Research Project: protocols for long-term monitoring and data collection, published online by the authors. http://www.princeton.edu/ baboon/publications/Monitoring_Guide_NoChptV.pdf.

-Altmann J, Gesquiere L, Galbany J, Onyango PO, Alberts SC (2010). The life history context of reproductive aging in a wild primate model. Annals of the New York Academy of Sciences 1204: 127-138.

Bailey SE (2004). A morphometric analysis of maxillary molar crowns of Middle-Late Pleistocene hominins. Journal of Human Evolution 47: 183-198.

Bailey SE, Lynch JM (2005). Diagnostic differences in mandibular P4 shape between Neandertals and anatomically modern humans. American Journal of Physical Anthropology 126: 268-277.

- Bermúdez de Castro JM, Arsuaga JL, Pérez PJ (1997). Interproximal grooving in the Atapuerca-SH hominid dentitions. American Journal of Physical Anthropology 102: 369-376.

Cochard LR (1987). Postcanine tooth size in female primates. American Journal of Physical Anthropology 74: 47-54.

Cole TM, Smith FH (1987). An odontometric assessment of variability in Australopithecus afarensis. Human Evolution 2: 221-234.

Cuozzo FP, Sauther ML (2010). What is dental ecology? American Journal of Physical Anthropology 141(suppl 50): 89.

De Gusta D, Everett MA, Milton K (2003). Natural selection on molar size in a wild population of howler monkeys (Alouatta palliata). Proceedings of the Royal Society of London B (Suppl) 270: S15-S17.

Delson E (1993). Theropithecus fossils from Africa and India and the taxonomy of the genus. In Theropithecus - The Rise and Fall of a Primate Genus (Jablonski NG, ed.), pp 157-190. Cambridge, Cambridge University Press.

Dennis JC, Ungar PS, Teaford MF, Glander KE (2004). Dental topography and molar wear in Alouatta palliata from Costa Rica. American Journal of Physical Anthropology 125: 152-161.

El Zaatari S, Grine FE, Teaford MF, Smith HF (2005). Molar microwear and dietary reconstructions for fossil Cercopithecoidea from the Plio-Pleistocene deposits of South Africa. Journal of Human Evolution 49: 180-205.

Fayad JB, Levy JC, Yazbeck C, Cavezian R, Cabanis EA (2004). Eruption of third molars: relationship to inclination of adjacent molars. American Journal of Orthodontics and Dentofacial Orthopedics 125: 200-202.

Galbany J, Altmann J, Pérez-Pérez A, Alberts SC (2011). Age and individual foraging behavior predict tooth wear in Amboseli baboons. American Journal of Physical Anthropology 144: 51-59.

Galbany J, Estebaranz F, Martínez LM, Pérez-Pérez A (2009). Buccal dental microwear variability in extant African Hominoidea primates: taxonomy versus ecology. Primates 50: 221-230.

Galbany J, Estebaranz F, Martínez LM, Romero A, De Juan J, Turbón D, Pérez-Pérez A (2006). Comparative analysis of dental enamel polyvinylsiloxane impression and polyurethane casting methods for SEM research. Microscopy Research and Technique 69: 246-252.

Galbany J, Martínez LM, Pérez-Pérez A (2004). Tooth replication techniques, SEM imaging and microwear analysis in primates: methodological obstacles. Anthropologie 41: 5-12.

Galbany J, Moyà-Solà S, Pérez-Pérez A (2005). Dental microwear variability on buccal tooth enamel surfaces of extant Catarrhini and fossil Miocene Hominoidea Dryopithecus laietanus. Folia Primatologica 76: 325-341.

-Garn SM, Lewis AB, Dahlberg AA, Kerewsky RS (1966). Interaction between relative molar size and relative number of cusps. Journal of Dental Research 45: 1240.

-Gençturk I, Alpagut B, Andrews P (2008). Interproximal wear facets and tooth associations in the Paşalar hominoid sample. Journal of Human Evolution 54: 480-493.

Godfrey LR, Samonds KE, Jungers WL, Sutherland MR (2001). Teeth, brains and primate life histories. American Journal of Physical Anthropology 114: 192-214.

- Godfrey LR, Semprebon GM, Jungers WL, Sutherland MR, Simons EL, Solounias N (2004). Dental use wear in extinct lemurs: evidence of diet and niche differentiation. Journal of Human Evolution 47: $145-170$. 
Gómez-Robles A, Martinón-Torres M, Bermúdez de Castro JM, Margvelashvili A, Bastir M, Arsuaga JL, Pérez-Pérez A, Estebaranz F, Martínez LM (2007). A geometric morphometric analysis of hominin upper first molar shape. Journal of Human Evolution 53: 272-285.

Gómez-Robles A, Martinón-Torres M, Bermúdez de Castro JM, Prado L, Sarmiento S, Arsuaga JL (2008). Geometric morphometric analysis of the crown morphology of the lower first premolar of hominins, with special attention to Pleistocene Homo. Journal of Human Evolution 55: 627-638.

Groves C, Harding J (2003). Morphology, morphometrics and taxonomy. In Field and Laboratory Methods in Primatology (Setchell JM, Curtis DJ, eds.), pp 140-157. Cambridge, Cambridge University Press.

Hayes VJ, Freedman L, Oxnard CE (1990). The taxonomy of savannah baboons: an odontomorphometric analysis. American Journal of Primatology 22: 171-190.

Hillson S, FitzGerald C, Flinn H (2004). Alternative dental measurements: proposals and relationships with other measurements. American Journal of Physical Anthropology 126: 413-426.

Hinton RJ (1982). Differences in interproximal and occlusal tooth wear among prehistoric Tennessee Indians: implications for masticatory function. American Journal of Physical Anthropology 57: $103-115$.

Hlusko LJ, Weiss KM, Mahaney MC (2002). Statistical genetic comparison of two techniques for assessing molar crown size in pedigreed baboons. American Journal of Physical Anthropology 117: 182189.

Kahumbu P, Eley RM (1991). Teeth emergence in wild olive baboons in Kenya and formulation of a dental schedule for aging wild baboon populations. American Journal of Primatology 23: 1-9.

Kaidonis JA, Townsend GC, Richards LC (1992). Interproximal tooth wear: a new observation. American Journal of Physical Anthropology 88: 105-107.

Kaifu Y, Kasai K, Townsend GC, Richards LC (2003). Tooth wear and the 'design' of the human dentition: a perspective from evolutionary medicine. Yearbook of Physical Anthropology 46: 47-61.

Kay RF (1975). The functional adaptations of primate molar teeth. American Journal of Physical Anthropology 43: 195-216.

Kay RF, Cant JGH (1988). Age assessment using cementum annulus counts and tooth wear in a freeranging population of Macaca mulatta. American Journal of Primatology 15: 1-15.

Kieser JA (1990). Human Adult Odontometrics. Cambridge, Cambridge University Press.

Kieser JA, Groeneveld HT, Preston CB (1985). Patterns of dental wear in the Lengua Indians of Paraguay. American Journal of Physical Anthropology 66: 21-29.

King SJ, Arrigo-Nelson SJ, Pochron ST, Semprebon GM, Godfrey LR, Wright PC, Jernvall J (2005). Dental senescence in a long-lived primate links infant survival to rainfall. Proceedings of the National Academy of Sciences 102: 16579-16583.

Martinón-Torres M, Bastir M, Bermúdez de Castro JM, Gómez A, Sarmiento S, Muela A, Arsuaga JL (2006). Hominin lower second premolar morphology: evolutionary inferences through geometric morphometric analysis. Journal of Human Evolution 50: 523-533.

Murphy T (1964). Reduction of the dental arch by approximal attrition. British Dental Journal 116: $483-488$.

Nystrom P, Phillips-Conroy JE, Jolly CJ (2004). Dental microwear in anubis and hybrid baboons (Papio hamadryas, sensu lato) living in Awash National Park, Ethiopia. American Journal of Physical Anthropology 125: 279-291.

Oxnard CE, Lieberman SS, Gelvin BR (1985). Sexual dimorphisms in dental dimensions of higher primates. American Journal of Primatology 8: 127-152.

Phillips-Conroy JE, Jolly CJ (1988). Dental eruption schedules of wild and captive baboons. American Journal of Primatology 15: 17-29.

Phillips-Conroy JE, Bergman T, Jolly CJ (2001). Quantitative assessment of occlusal wear and age estimation in Ethiopian and Tanzanian baboons. In Old World Monkeys (Jolly CJ, Whitehead P, eds.), pp 321-340. Cambridge, Cambridge University Press.

Post DG (1981). Activity patterns of yellow baboons (Papio cynocephalus) in the Amboseli National Park, Kenya. Animal Behaviour 29: 357-374.

Post DG, Hausfater G, McCuskey SA (1980). Feeding behavior of yellow baboons (Papio cynocephalus): relationship to age, gender and dominance rank. Folia Primatologica 34: 170-195.

Reed OM (1973). Papio cynocephalus age determination. American Journal of Physical Anthropology 38: 309-314.

Sauther ML, Cuozzo FP, Sussman RW (2001). Analysis of dentition of a living wild population of ringtailed lemurs (Lemur catta) from Beza Mahafaly, Madagascar. American Journal of Physical Anthropology 114: 215-223.

Southard TE, Behrents RG, Tolley EA (1989). The anterior component of occlusal force. 1. Measurement and distribution. American Journal of Orthodontics and Dentofacial Orthopedics 96: 493-500.

Southard TE, Southard KA, Tolley EA (1992). Periodontal force: a potential cause of relapse. American Journal of Orthodontics and Dentofacial Orthopedics 101: 221-227. 
Swindler DR (2002). Primate Dentition: An Introduction to the Teeth of Non-Human Primates. Cambridge, Cambridge University Press.

- Swindler DR, Orlosky FJ (1974). Metric and morphological variability in the dentition of colobine monkeys. Journal of Human Evolution 3: 135-160.

- Teaford MF (1994). Dental microwear and dental function. Evolutionary Anthropology 3: 17-30.

Teaford MF (2000). Primate dental functional morphology revisited. In Development, Function and Evolution of Teeth (Teaford MF, Smith MM, Ferguson MWJ, eds.), pp 290-304. Cambridge, Cambridge University Press.

Teaford MF, Ungar PS (2000). Diet and the evolution of the earliest human ancestors. Proceedings of the National Academy of Sciences 97: 13506-13511.

Teschler-Nicola M, Prossinger H (1998). Sex determination using tooth dimensions. In Dental Anthropology: Fundamentals, Limits, and Prospects (Alt KW, Rösing FW, Teschler-Nicola M, eds.), pp 479-500. Berlin, Springer.

Tung J, Charpentier MJE, Garfield D, Altmann J, Alberts SC (2008). Genetic evidence reveals temporal change in hybridization patterns in a wild baboon population. Molecular Ecology 17: 1998-2011.

Uitenbroek DG (1997). SISA-binomial. http://www.quantitativeskills.com/sisa/ (accessed January 1, 2004).

Ungar PS (1990). Incisor microwear and feeding behavior in Alouatta seniculus and Cebus olivaceus. American Journal of Primatology 20: 43-50.

Ungar PS, Teaford MF, Kay RF (2004). Molar microwear and shearing crest development in Miocene catarrhines. Anthropologie 42: 21-35.

-Warton DI, Wright JJ, Falster DS, Westoby M (2006). Bivariate line-fitting methods for allometry. Biology Reviews 81: 259-291.

Welsch U (1967). Tooth wear in living pongids. Journal of Dental Research 46: 989-992.

Whittaker DK, Ryan S, Weeks K, Murphy WM (1987). Patterns of approximal wear in cheek teeth of a Romano-British population. American Journal of Physical Anthropology 73: 389-396.

-Wolpoff MH (1971). Interstitial wear. American Journal of Physical Anthropology 34: 205-228.

-Wood BA (1981). Tooth size and shape and their relevance to studies of hominid evolution. Philosophical Transactions of the Royal Society of London B 292: 65-76.

Wood BA, Engleman CA (1988). Analysis of the dental morphology of Plio-Pleistocene hominids. V. Maxillary postcanine tooth morphology. Journal of Anatomy 161: 1-35.

Wood BA, Uytterschaut H (1987). Analysis of the dental morphology of Plio-Pleistocene hominids. III. Mandibular premolar crowns. Journal of Anatomy 154: 121-156.

-Wood BA, Li Y, Willoughby C (1991). Intraspecific variation and sexual dimorphism in cranial and dental variables among higher primates and their bearing on the hominid fossil record. Journal of Anatomy 174: 185-205.

Wright P, King SJ, Baden A, Jernvall J (2008). Aging in wild female lemurs: sustained fertility with increased infant mortality. In Primate Reproductive Aging (Atsalis S, Margulis SW, Hof PR, eds.), Interdisciplinary Topics in Gerontology vol 36, pp 17-28. Basel, Karger.

Zohdy S, King SJ, Wright PC, Jernvall J (2009). Longevity in wild mouse lemurs: old but not mousy. American Journal of Physical Anthropology 138(suppl 48): 280. 